\title{
Dominique Viart, Commente «Vies minuscules» de Pierre Michon
}

\section{Rosa Galli Pellegrini}

\section{Q OpenEdition}

1 Journals

\section{Edizione digitale}

URL: http://journals.openedition.org/studifrancesi/36746

DOI: 10.4000/studifrancesi.36746

ISSN: 2421-5856

\section{Editore}

Rosenberg \& Sellier

\section{Edizione cartacea}

Data di pubblicazione: 1 juillet 2005

Paginazione: 203

ISSN: 0039-2944

\section{Notizia bibliografica digitale}

Rosa Galli Pellegrini, «Dominique Viart, Commente «Vies minuscules» de Pierre Michon», Studi Francesi

[Online], 145 (XLIX | I) | 2005, online dal 30 novembre 2015, consultato il 18 avril 2021. URL: http:// journals.openedition.org/studifrancesi/36746 ; DOI: https://doi.org/10.4000/studifrancesi.36746

Questo documento è stato generato automaticamente il 18 avril 2021.

\section{(c) $(1) \&$}

Studi Francesi è distribuita con Licenza Creative Commons Attribuzione - Non commerciale - Non opere derivate 4.0 Internazionale. 


\title{
Dominique Viart, Commente «Vies minuscules» de Pierre Michon
}

\author{
Rosa Galli Pellegrini
}

\section{NOTIZIA}

DOMINIQUE VIART, Commente «Vies minuscules» de Pierre Michon, Paris, Gallimard («Folio»), 2004, pp. 188.

1 Uno dei maggiori specialisti della letteratura contemporanea ci guida nella lettura di Vies minuscules, iniziando dall'analisi della struttura narrativa dell'opera. Il contesto biografico e la sua relazione con un progetto agiografico rappresentano il secondo luogo del commento che è seguito dalla problematica del racconto autobiografico, o meglio dell'autobiografismo, presenza costante (e malcelata) in questo testo michoniano. Un'altro elemento critico, che si giustifica anche dalle ripetute dichiarazioni dello stesso autore, concerne il rapporto del romanziere con la lingua e la ricerca stilistica oltre che con la cultura letteraria e artistica da lui acquisita nel tempo. Non viene tralasciato il rapporto dello scrittore, e la sua identificazione trasversale, con Rimbaud. L'agile volume è un utilissimo strumento di introduzione alla lettura del testo ed è inoltre corredato da un ricco dossier di comoda consultazione. 